Revista Brasileira de Agricultura Irrigada v.8, nº.6, p.432 - 443, 2014

ISSN 1982-7679 (On-line)

Fortaleza, CE, INOVAGRI - http://www.inovagri.org.br

DOI: $10.7127 /$ rbai.v8n600244

Protocolo 244.14 - 26/04/2014 Aprovado em 28/08/2014

\title{
GENÓTIPOS DE AMENDOIM CULTIVADOS EM SEMEADURA DIRETA E CONVENCIONAL SOB REGIME HÍDRICO DO SUDOESTE GOIANO
}

\author{
Taylon Lima Carvalho ${ }^{1}$, Anísio Correa da Rocha ${ }^{2}$, Fabiano José de Campos Bastos ${ }^{3}$, \\ Fernando Nobre Cunha ${ }^{4}$,Nelmício Furtado da Silva ${ }^{5}$, Frederico Antônio Loureiro Soares ${ }^{4}$
}

\section{RESUMO}

O amendoim é uma espécie pertencente à família Fabaceae e ao gênero Arachis. É uma planta dicotiledônea, herbácea, anual, destacando-se a Arachishypogea L. como a mais importante entre as espécies cultivadas. O plantio direto promove ao solo vários benefícios, como: proteção contra o impacto direto das gotas de chuva, redução da perda de água por escoamento superficial, favorecimento da infiltração, e da perda de solo e nutrientes por erosão. O experimento foi conduzido na área experimental do Instituto Federal de Educação, Ciência e Tecnologia Goiano - Campus Rio Verde, com o objetivo de verificar o efeito de três variedades: BRS Havana, Tatu, BR1 e a linhagem 283 AM, cultivadas em semeadura direta e convencional. O delineamento experimental utilizado foi blocos casualizados com 8 tratamentos, em esquema fatorial 4 x 2 e 4 repetições. Constatou-se apenas em peso de 100 vagens e peso de grãos de 100 vagens diferença significativa entre os tipos de plantio, onde destaca-se a cultivar BRS Havana, no sistema de plantio direto para peso de grãos de 100 vagens. Para peso de 100 vagens em sistema de plantio convencional a cultivar BRS Havana foi a que apresentou pior desempenho. A produtividade foi estimada em função do rendimento de vagens na área útil de cada parcela, Todos os tratamentos apresentaram produtividades estatisticamente iguais, com produtividades superiores a $1.400 \mathrm{~kg} \mathrm{ha}^{-1}$, observando-se a seguinte ordem crescente: Tatu $>283$ AM $>$ BR1 > BRS Havana.

Palavras-chave: Arachishypogaea L, cultivares, tipo de semeadura, produtividade.

\footnotetext{
${ }^{1}$ Engenheiro Agrônomo, Instituto Federal Goiano - Campus Rio Verde. Rodovia Sul Goiana km 01, CEP 75901-970, Rio Verde, GO. E-mail: taylonagro@gmail.com.

2 Eng. Agrônomo, Prof. Dr. em Agronomia, IFGoiano - Campus Rio Verde, e-mail: anisiorocha@yahoo.com.br

${ }^{3}$ Mestrando em Ciências Agrárias - Agronomia, Instituto Federal Goiano - Campus Rio Verde, Rodovia Sul Goiana, Km 01, CEP: 75.901-170, Rio Verde-GO, e-mail: fabianojcbastos@gmail.com

${ }^{4}$ Doutorando em Ciências Agrárias - Agronomia, Instituto Federal Goiano - Campus Rio Verde, Rodovia Sul Goiana, Km 01, CEP: 75.901-170, Rio Verde-GO, e-mail: fernandonobrecunha@hotmail.com

${ }^{5}$ Doutorando em Ciências Agrárias - Agronomia, Instituto Federal Goiano - Campus Rio Verde, Rodovia Sul Goiana, Km 01, CEP: 75.901-170, Rio Verde - GO, e-mail: nelmiciofurtado@gmail.com

6 Eng. Agrônomo, Prof. Dr. em Agronomia, IFGoiano - Campus Rio Verde, e-mail: fredalsoraes@hotmail.com
} 


\title{
GENOTYPES PEANUT GROWN IN DIRECT SEEDING AND CONVENTIONAL UNDER WATER REGIME OF SOUTHWEST GOIANO
}

\begin{abstract}
Peanut is a species belonging to the Fabaceae family and genus Arachis. It's a dicot plant, herbaceous, annual, highlighting the Arachis hypogea L. as the most important among the cultivated species. The straight planting promotes to the ground several benefits, as protection against the straight impact of the drops of rain, reduction of the water loss for superficial drainage, favoring the infiltration, and the ground loss and nutritious for erosion. The experiment was conducted in the experimental area of the Federal Institute of Education, Science and Technology Goiás - Campus Rio Verde, in order to verify the effect of three varieties: BRS Havana, Tatu, BR1 and the lineage 283 AM, grown by direct seeding and conventional. The experimental design was randomized blocks with eight treatments in a factorial $4 \times 2$ and 4 replications. It was found only in weight of 100 pods and grain weight of 100 pods significant difference between the types of planting, which stands out BRS Havana, in tillage for grain weight of 100 pods. Weight of 100 pods in conventional tillage BRS Havana system showed the worst performance. Productivity was estimated according to the yield of pods in the floor area of each plot All treatments had statistically similar yields, with more than $1400 \mathrm{~kg} \mathrm{ha}^{-1}$ yields, observing the following order: Tatu> 283 MB> BR1> BRS Havana.
\end{abstract}

Keywords: ArachishypogaeaL, cultivars, type of seeding, productivity.

\section{INTRODUÇÃO}

Entre as oleaginosas cultivadas no mundo, atualmente, o amendoim está na quarta posição, ocupando cerca de 23 milhões de hectares. Em termos de importância econômica, esta oleaginosa fica atrás apenas da soja (41,8\% do total mundial), do algodão $(14,1 \%)$ e da colza $(13,1 \%)$ e participa com cerca de $10 \%$ da produção mundial de oleaginosas (FAO, 2013).

No Brasil, a cultura é explorada em larga escala no estado de São Paulo, que responde por cerca de $80 \%$ da produção nacional, o que representou aproximadamente 293 mil toneladas na safra de 2012-2013. Atualmente a produção nacional de amendoim é de aproximadamente 326 mil toneladas. $\mathrm{Na}$ safra de 2011-2012, o Estado de Goiás plantou aproximadamente 1.000 ha da oleaginosa, com produtividade média de $2.300 \mathrm{~kg} \mathrm{ha}^{-1}$ e apesar de ser pouco plantada em Goiás, a produ- tividade média está entre as três melhores do país, o que indica um potencial para a produção de amendoim no Estado de Goiás (CONAB, 2013).

Segundo Santos et al. (2006), na agricultura brasileira, o amendoim tem se destacado por ser de fácil manejo, ciclo curto e pelo bom preço, além das várias formas em que o produto é utilizado (consumo in natura, processados, óleos e combustível alternativo), o que incentiva a produção e expansão desta cultura.

Segundo Doorenbos \& Kassam (1994), a cultura do amendoim necessita de aplicação de 500 a $700 \mathrm{~mm}$ de água durante o seu ciclo de cultivo para expressar seu ótimo potencial produtivo.

No Brasil e em outros países, estudos comparativos são desenvolvidos, quanto à viabilidade da implantação da cultura do amendoim, entre o sistema de plantio direto e o 
sistema de plantio convencional. Resultados indicam que o desenvolvimento e aprimoramento da tecnologia da semeadura direta do amendoim, será possível cultivá-lo em áreas de colheita de cana crua (BOLONHEZI et al., 2007), reforma de pastagens e em rotação com culturas, o que proporcionará maior sustentabilidade na produção do amendoim.

São vários os benefícios ambientais que um sistema sustentável de produção proporciona. O principal deles é a redução da erosão do solo com a boa quantidade de palha que fica disposta na superfície. Outro importante benefício é a melhor eficiência do uso da água, pelo fato de o sistema de plantio direto diminuir a erosão, faz com que o solo absorva mais água (HERMANI et al., 1999). Além disso, há o benefício de redução das aplicações de herbicidas, diminuição da contaminação do lençol freático e dos cursos d'água. Mas, no caso do plantio direto de amendoim, também são expressivos os ganhos econômicos. Os produtores de amendoim chegam a economizar mais de $30 \%$ dos custos de produção e conseguem manter o mesmo nível de produtividade do sistema de plantio tradicional.

Neste contexto, atualmente, os centros de pesquisa têm dado grande ênfase à adaptação de culturas ao sistema plantio direto, buscando um aumento no número de opções disponíveis para compor os esquemas de rotação, prática que se constitui em um dos pilares para o sucesso desse sistema de manejo do solo. Visto o grande potencial deste cultivo, é importante conhecer o desempenho das cultivares e linhagens nas condições climáticas do Sudoeste Goiano nos diferentes sistemas de plantio.

Objetivou-se com esse trabalho avaliar as cultivares de amendoim BR1, BRS Havana, Tatu e a linhagem 283 AM, cultivadas em semeadura direta e convencional no regime hídrico do Sudoeste Goiano.

\section{MATERIAL E MÉTODOS}

O trabalho foi desenvolvido na área experimental do Instituto Federal de Educação, Ciência e Tecnologia Goiano - Campus Rio Verde, no período de janeiro a maio de 2011. A Região apresenta clima tropical Aw (KOPPEN \& GEIGER, 1928), com estação chuvosa e seca bem definida, relevo levemente ondulado, com precipitação pluviométrica anual de $1.740 \mathrm{~mm}$, numa altitude média de 716 m e localização geográfica nas coordenadas $20^{\circ} 45^{\prime}$ 53'” de latitude sul e 51 55'53'” de longitude Oeste.

A partir dos dados climatológicos do período experimental, foi elaborada a estimativa do balanço hídrico decendial para o amendoim (Figura 1).

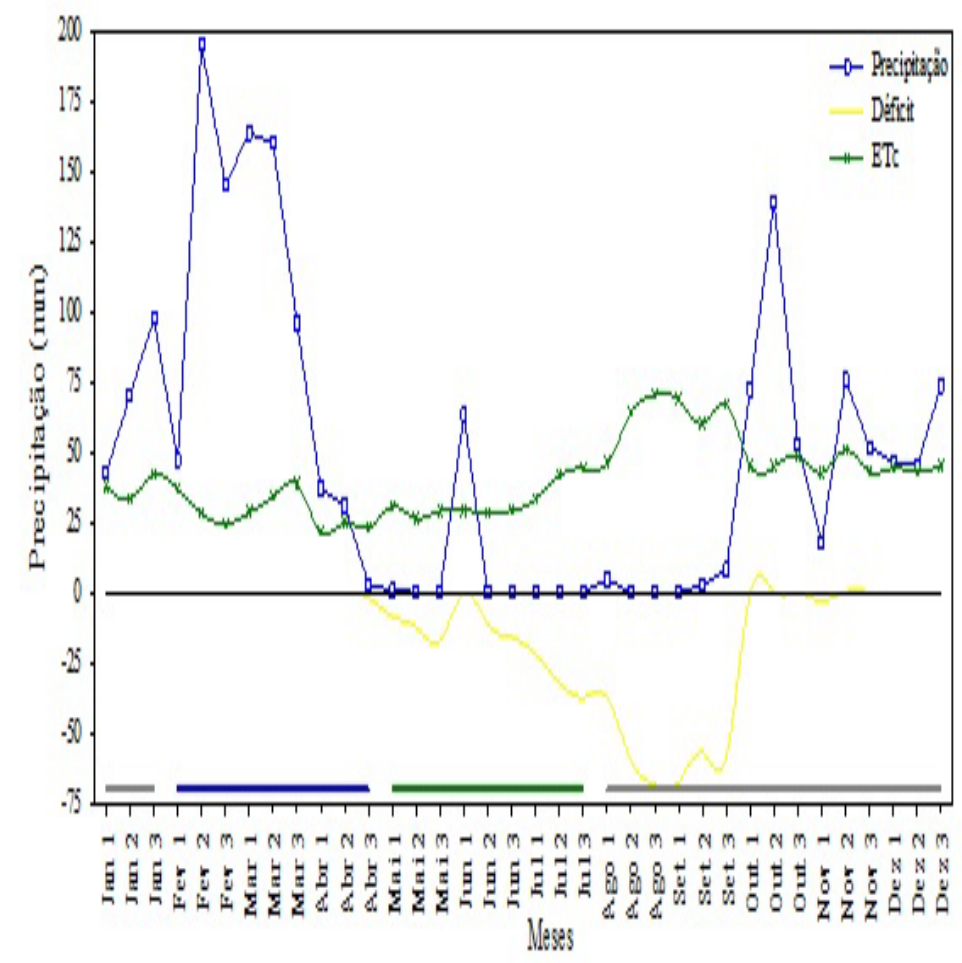

Figura 1. Balanço hídrico decendial no período decorrente do experimento para o amendoim para o ano de 2011.

Fonte: Estação Normal INMET - Rio Verde - GO. 
Carvalho et al.

O solo da área experimental é classificado como Latossolo Vermelho distroférrico (LVdf) de textura média (EMBRAPA, 2006) e, para fins de caracterização físico química do solo, foram coletadas e enviadas amostras na profundidade de $0-20 \mathrm{~cm}$ ao Laboratório de Solos do IFGoiano- Campus Rio Verde (Tabela 1) para realização da correção e adubação do solo.

Tabela 1. Análise físico-química do solo da área experimental.

\begin{tabular}{cccccc}
\hline $\mathrm{pH}$ & Argila & $\mathrm{P}$ & $\mathrm{K}$ & $\mathrm{Ca}$ & $\mathrm{Mg}$ \\
\hline $\mathrm{H}_{2} \mathrm{O}$ & $\mathrm{g} \mathrm{Kgkg}^{-1}$ & $\mathrm{mgdm}^{-3}$ & & $\mathrm{mmol} \mathrm{dm}^{-3}$ & \\
6,28 & 500 & 80,8 & 9,4 & 47,7 & 17,7 \\
\hline
\end{tabular}

Utilizou-se o delineamento experimental de blocos casualizados, em esquema fatorial 4 x 2 com 4 repetições, num total de 32 parcelas experimentais.

Os tratamentos foram compostos pela combinação dos seguintes fatores: quatro cultivares de amendoim (BR-1, BRS Havana, Tatu e a linhagem 283 AM) e dois tipos de plantio (sistema de plantio direto e sistema de plantio convencional).

Na implantação do experimento, primeiramente, procedeu-se a dessecação da área toda coberta com palhada (Urochloabrizantha (Stapf) Webster cv. Marandu) e nas parcelas experimentais que receberam o plantio convencional realizou-se uma aração seguida de gradagem. Nas parcelas correspondentes ao plantio direto manteve-se a palhada.

A adubação foi realizada de acordo com a análise de solo (Tabela 1) e as recomendações da Embrapa (2004), para a cultura do amendoim no cerrado, no sulco de semeadura.

A semeadura foi realizada no dia 26 de janeiro de 2011, utilizando uma área expe- rimental total de $419 ., 75 \mathrm{~m}^{2}$, (11,5 x 36.,5 m²), com largura de $0,5 \mathrm{~m}$ de bordadura e entre parcelas, o restante da área $\left(288 \mathrm{~m}^{2}\right)$ dividida em 32 unidades experimentais cada uma com 4,0 m de comprimento por 2,25 m de largura (9 $\mathrm{m}^{2}$ ), com cinco linhas espaçadas a $0,45 \mathrm{~m}$ e a densidade de 12 sementes por metro linear. Em cada parcela experimental foram avaliadas as três linhas centrais, desprezando-se as duas linhas externas e $0,5 \mathrm{~m}$ das extremidades de cada parcela.

O controle de pragas, doenças e plantas daninhas foi realizado de acordo com as necessidades, para um bom desempenho da cultura. Foram realizadas duas capinas manuais para o controle de plantas daninhas.

Durante a condução do experimento houve incidência de algumas pragas como: trips, mosca branca, cigarrinha e lagartas (principalmente a lagarta elasmo), controladas com inseticidas recomendados para a cultura, em duas aplicações, sendo elas efetuadas quando o ataque atingia o nível de dano econômico, determinado através de amostragens diárias. As formigas foram controladas com iscas em quatro aplicações, de acordo com a identificação de danos causados na cultura.

A colheita do experimento foi realizada manualmente, quando aproximadamente $75 \%$ das vagens encontravam-se maduras, no dia 30 de maio de 2011. Em seguida, foi realizada a secagem do amendoim sob o sol por uma semana.

As variáveis analisadas foram: número de vagens por planta (NVP), peso de cem grãos (P100G), peso de cem vagens (P100V), peso de área útil (PAU), número de grãos de cem vagens (NG100V), peso de grãos de cem vagens (PG100V), produtividade de grãos (PROD) e rendimento (RED).

A produtividade foi estimada em função 
do rendimento de vagens na área útil de cada parcela. O número de vagens por planta foi obtido pela amostragem de 10 plantas por parcela.

O peso médio de grãos foi determinado utilizando-se uma amostragem de 100 grãos por parcela. O rendimento de grãos foi obtido pelo quociente entre o peso de grãos obtido em 100 vagens e o peso de 100 vagens.

Os dados coletados foram submetidos à análise de variância, utilizando-se o programa estatístico SISVAR (FERREIRA, 2011) e as médias foram comparadas pelo teste de Tukey a $5 \%$ de probabilidade.

\section{RESULTADOS E DISCUSSÃO}

O balanço hídrico apresentado na Figura 1 permitiu observar a influência dos fatores climáticos no desenvolvimento das plantas de amendoim sob manejo de sequeiro, visando demonstrar o estresse hídrico sofrido pela cultura. A evapotranspiração total durante o ciclo de 395 dias foi de $1.400 \mathrm{~mm}$, enquanto a precipitação foi de $1.618 \mathrm{~mm}$.

A precipitação total ao longo do ciclo da cultura do amendoim coletada in loco, foi de 876,5 mm, retirando o volume de água percolado foram computados 469,7 $\mathrm{mm}$ de precipitação efetiva (PE). A evapotranspiração total do ciclo da cultura (ETc) totalizou 880,5 $\mathrm{mm}$.

A cultura do amendoim, quando envolve genótipos submetidos a períodos curtos e moderados de estresse hídrico, tem demonstrado tolerância a ambientes com baixa ou irregular disponibilidade de água. No entanto, mesmo havendo tolerância, o estresse hídrico é crítico quando ocorre a partir da floração e no enchimento dos grãos, sendo mais expressivo nos genótipos de hábito rasteiro, podendo comprometer a produção (SANTOS et al., 2010; AZEVEDO NETO et al., 2010; JONGRUNGKLANG et al., 2011; PEREIRA et al., 2012).

Na Tabela 2, observa-se que, entre o tipo de plantio, houve diferença significativa para o peso de 100 Vagens (P100V) e o peso de grãos de 100 vagens (PG100V) a 5 e 1\% de probabilidade, respectivamente. Nas cultivares, apenas o número de vagens por planta (NVP) não apresentou diferença significativa entre elas. Para a interação tipo de plantio e cultivar, nota-se diferença significativa a $5 \%$ de probabilidade para o peso de 100 Vagens (P100V) e peso de grãos de 100 vagens (PG100V).

Tabela 2 - Resumo da análise de variância para as variáveis número de vagens por planta (NVP), peso de 100 grãos (P100G), Peso de 100 Vagens (P100V), peso de grãos de 100 vagens (PG100V) das cultivares e linhagem de amendoim em diferentes tipos de plantio.

\begin{tabular}{|c|c|c|c|c|c|}
\hline \multirow{2}{*}{$\begin{array}{l}\text { Fonte de } \\
\text { variação }\end{array}$} & \multirow{2}{*}{ GL } & \multicolumn{4}{|c|}{ Quadrados Médios } \\
\hline & & NVP & P100G & P100V & PG100V \\
\hline $\begin{array}{l}\text { Tipo Plantio } \\
\text { (TP) }\end{array}$ & 1 & $338,00^{\text {ns }}$ & $0,46^{\mathrm{ns}}$ & $385,03^{*}$ & $348,74^{* *}$ \\
\hline Cultivar (C) & 3 & $603,37^{\mathrm{ns}}$ & $198,77^{* *}$ & $7038,40^{* *}$ & $3874,12^{* *}$ \\
\hline $\begin{array}{l}\text { Interação } \\
\text { TP x C }\end{array}$ & 3 & $27,25^{\mathrm{ns}}$ & $10,58^{\mathrm{ns}}$ & $203,91^{*}$ & $155,83^{*}$ \\
\hline Bloco & 3 & $336,37^{\mathrm{ns}}$ & $15,75^{\mathrm{ns}}$ & $71,09^{\text {ns }}$ & $28,09^{\text {ns }}$ \\
\hline Resíduo & 21 & 493,56 & 6,55 & 58,93 & 39,00 \\
\hline CV (\%) & & 13,22 & 5,32 & 4,63 & 4,87 \\
\hline $\begin{array}{l}{ }^{\text {ns Não sig }} \\
\text { probabilid } \\
\text { de variaçã }\end{array}$ & & ${ }^{* *} \mathrm{e}$ & ifi & $\begin{array}{l}0 \text { a } 1 \\
C V-C\end{array}$ & $\begin{array}{l}5 \% \text { de } \\
\text { iciente }\end{array}$ \\
\hline
\end{tabular}


Observando a Figura 2, verifica-se que o peso de 100 grãos (P100G) da cultivar 283 AM superou estatisticamente as demais cultivares, com diferença de 54,22 g, sendo superior em $8,67,14,63$ e $21,69 \%$ o peso de 100 grãos das cultivares BRS Havana, BR 1 e Tatu, respectivamente; as cultivares BRS Havana e BR 1 obtiveram valores de P100G estatisticamente iguais, porém diferiram da cultivar Tatu.

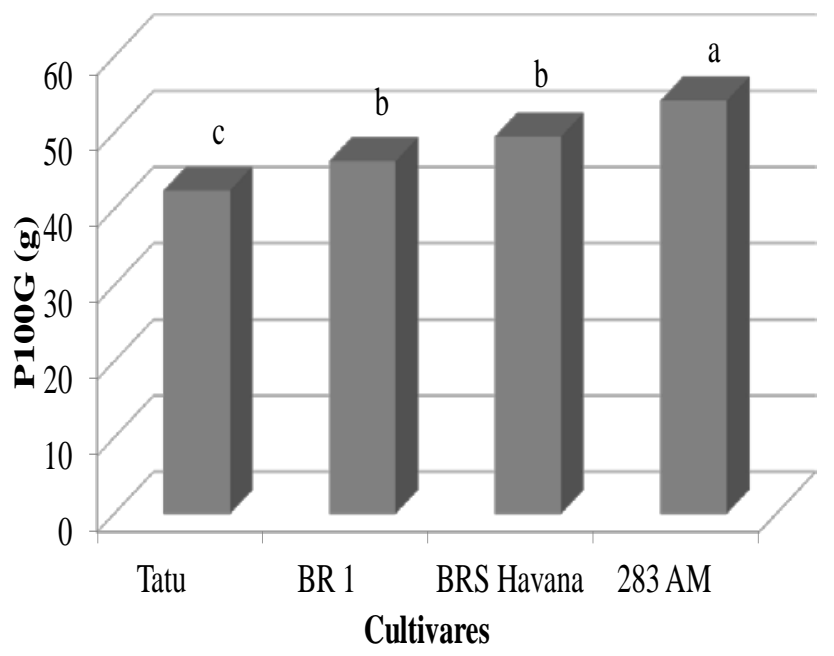

Figura 2. Médias dos pesos de 100 grãos (P100G) das cultivares de amendoim nos sistemas de cultivo.

Os resultados das médias obtidas para o peso de 100 grãos (P100G) indicam que, nas condições do experimento, a cultivar 283 AM foi a que demonstrou maior peso, conforme apresentado na Figura 2; além de ótima qualidade dos grãos produzidos, atendendo principalmente as exigências das indústrias alimentícias.

O desdobramento da interação significativa para o peso de 100 vagens (P100V) pode ser verificado na Figura 3. Observando o desdobramento dos tipos de plantio dentro de cada cultivar (Figura 3A), nota-se que só houve diferença significativa entre os tipos de plantio no P100V para a cultivar BRS Havana, com o plantio direto superando o plantio convencional em 10,2\%.
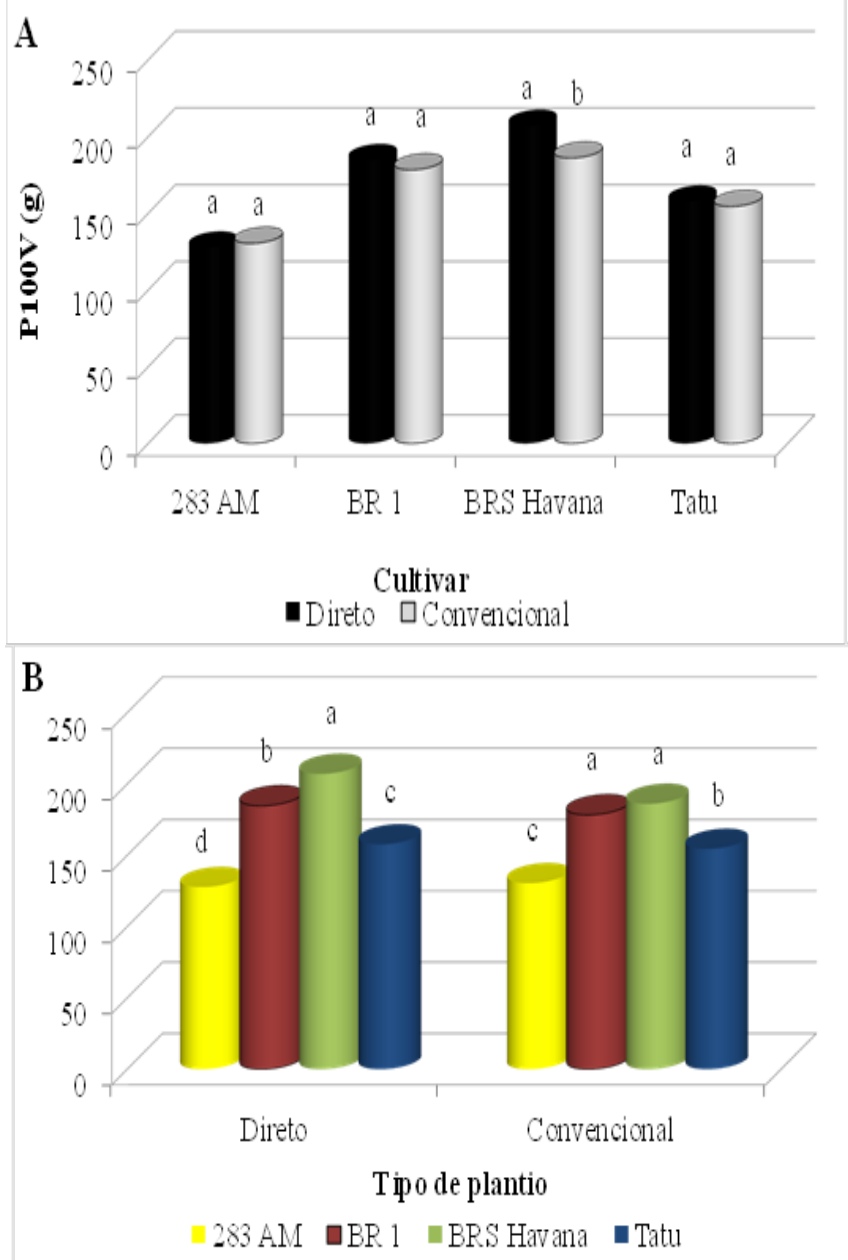

Figura 3. Peso de 100 vagens (P100V) do amendoim em dois tipos de plantio para cada cultivar estudada (A) e das cultivares dentro de cada tipo de plantio (B).

Por outro lado, observando o desdobramento das cultivares dentro de cada tipo de plantio (Figura 3B), verifica-se que quando o amendoim é plantado no sistema de plantio direto a cultivar BRS Havana obtém o peso de 100 vagens estatisticamente maior que as demais cultivares. Já a cultivar BR 1 foi estatisticamente inferior a BRS Havana e superior as cultivares Tatu e linhagem 283 AM. Em relação a cultivar Tatu observa-se que o P100V foi estatisticamente diferente à linhagem 283 AM, a qual apresentou um peso de 100 vagens, 44,6, 62,2 e 23,4\% menor do que o verificado nas cultivares BR 1 , BRS Havana e Tatu, respectivamente. 
No desdobramento das cultivares dentro do plantio convencional (Figura 3B), constatase que as cultivares BRS Havana e BR 1 demonstraram P100V semelhantes, os quais entretanto diferiram da cultivar Tatu e dalinhagem 283 AM. O P100V da cultivar Tatu foi $15,6 \%$ maior que o da linhagem 283 AM e consequentemente apresentou um P100V 15,45 e 20,45\% menor do que o das cultivares BR 1 e BRS Havana, respectivamente.

Observando o peso de grãos de 100 vagens (PG100V), pode-se verificar no desdobramento do tipo de plantio dentro de cada cultivar avaliada (Figura 4A) que houve diferença significativa entre os tipos de plantio. Observou-se que, o tipo de plantio direto foi superior ao plantio convencional para a cultivar BRS Havana em 11,70\%.
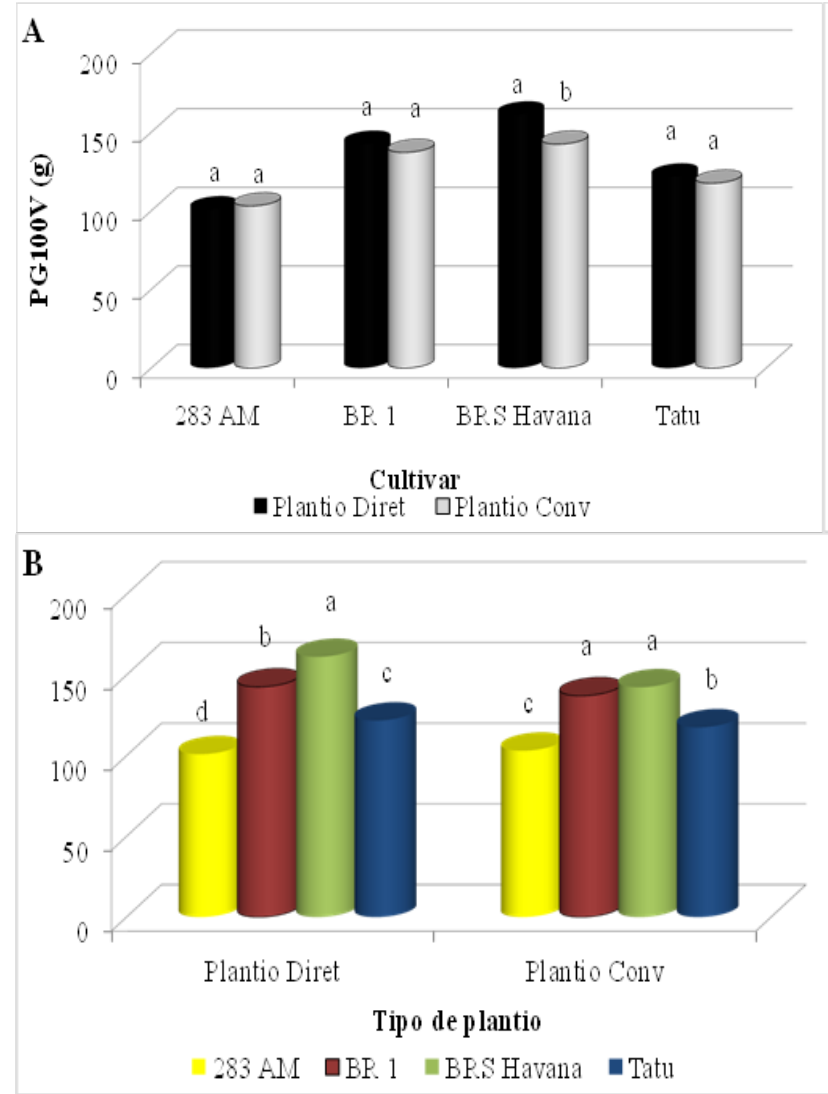

Figura 4. Peso de grãos de 100 vagens (PG100V) do amendoim em dois tipos de plantio para cada cultivar estudada (A) e das cultivares dentro de cada tipo de plantio (B). Plantio Diret -Plantio direto. Plantio Conv - Plantio convencional.
Já no desdobramento das cultivares dentro de cada tipo de plantio (Figura 4B), constata-se que quando o amendoim é cultivado no sistema de plantio direto, o peso de grãos de cem vagens (PG100V) da cultivar BRS Havana foi maior estatisticamente que as demais cultivares, enquantoque a cultivar BR1 apresentou-se estatisticamente superior às cultivares Tatu e 283 AM e inferior a BRS Havana. Com relação ao peso de grãos de cem vagens da cultivar Tatu, foi estatisticamente superior somente à cultivar 283 AM, e quando observou-se a cultivar 283 AM verificou-se que ela obteve um PG100V de 100,9 g com inferioridade de 37,4, 29,2 e 17,1\% do peso de grãos de cem vagens das cultivares BRS Havana, BR1 e Tatu, respectivamente.

Por outro lado, quando observa-se o desdobramento das cultivares dentro do plantio convencional (Figura 4B), verifica-se que o peso de grãos de cem vagens das cultivares BRS Havana e BR1 foram estatisticamente semelhantes, sendo superiores às cultivares Tatu e a linhagem 283 AM. Entre as cultivares Tatu e a linhagem 283 AM, a cultivar Tatu foi significativamente superior à linhagem 283 AM em 12,28\%, apresentando o peso de grãos de cem vagens de 117,51g. Observando-se o PG100V da linhagem 283 AM em relação ao das cultivares BRS Havana e BR1, apresentou estatisticamente uma inferioridade em 27,60 e $24,84 \%$, respectivamente.

Diante dos resultados pode-se afirmar que a cultivar mais indicada para ser utilizada nos dois tipos de plantio avaliados é a BRS Havana, principalmente no plantio direto, visto que os resultados obtidos neste trabalho constataram que, nas condições do experimento, a cultivar BRS Havana foi a que demonstrou superioridade. 
Carvalho et al.

De acordo com a Tabela 3, o número de grãos de 100 vagens (NG100V) e o rendimento do amendoim (REND) apresentaram significância com relação ao cultivar (C) e para o tipo de plantio. A produtividade (PROD) não apresentou diferença significativa entre as cultivares avaliadas e quanto ao tipo de plantio e também não apresentou significância na interação entre os dois fatores, demonstrando estatisticamente que neste experimento os cultivares em qualquer tipo de plantio irão apresentar uma mesma produção. Comportamento idêntico ao da produção foi observado para o peso de grãos, caracterizando que somente há diferença significativa quando comparados os genótipos dentro da variável.

Tabela 3 - Resumo da análise de variância para as variáveis número de grãos em 100 vagens (NG100V), peso da área útil (PAU), produtividade (PROD) e rendimento (REND) das cultivares e linhagem de amendoim em diferentes tipos de plantio

\begin{tabular}{|c|c|c|c|c|c|}
\hline \multirow{2}{*}{$\begin{array}{l}\text { Fonte de } \\
\text { variação }\end{array}$} & \multirow{2}{*}{ GL } & \multicolumn{4}{|c|}{ Quadrados Médios } \\
\hline & & NG100V & PAU & PROD & REND \\
\hline \multicolumn{6}{|l|}{ Tipo } \\
\hline $\begin{array}{l}\text { Plantio } \\
\text { (TP) }\end{array}$ & 1 & $2227,78^{\mathrm{ns}}$ & $19904,61^{\mathrm{ns}}$ & $121351,14^{\mathrm{ns}}$ & $0,00042^{\mathrm{ns}}$ \\
\hline $\begin{array}{l}\text { Cultivar } \\
\text { (C) }\end{array}$ & 3 & $32191,86^{* *}$ & $22516,47^{\mathrm{ns}}$ & $137274,62^{\mathrm{ns}}$ & $0,00091^{*}$ \\
\hline $\begin{array}{c}\text { Interação } \\
\text { TP x C }\end{array}$ & 3 & $291,28^{\mathrm{ns}}$ & $10630,80^{\mathrm{ns}}$ & $64812,04^{\mathrm{ns}}$ & $0,00009^{\mathrm{ns}}$ \\
\hline Bloco & 3 & $116,36^{\text {ns }}$ & $151233,98^{\mathrm{ns}}$ & $922018,10^{* *}$ & $0,00007^{\mathrm{ns}}$ \\
\hline Resíduo & 21 & 967,10 & 27884,02 & 169998,59 & 0,00022 \\
\hline CV (\%) & & 10,66 & 25,38 & 25,38 & 1,94 \\
\hline $\begin{array}{l}{ }^{\text {ns }} \text { Não } \\
\text { probab } \\
\text { de vari }\end{array}$ & (n) & $\begin{array}{l}\text { ativo. } \\
\text { GL - Gra }\end{array}$ & ${ }^{*}$ Siønifio & $\begin{array}{l}\text { vo a } 1 \text { e } \\
\text { CV }-\mathrm{Co}\end{array}$ & $\begin{array}{l}5 \% \text { de } \\
\text { ficiente }\end{array}$ \\
\hline
\end{tabular}

Na Figura 5A, encontra-se os valores médios do número de grãos em 100 vagens; pode-se verificar que as cultivares Tatu, BR 1 e BRS Havana não diferiram estatisticamente entre si e que a linhagem 283 AM produziu estatisticamente 62,26, 64,74 e 66,20\% menos grãos em 100 vagens que os cultivares Tatu, BR 1 e BRS Havana, respectivamente.
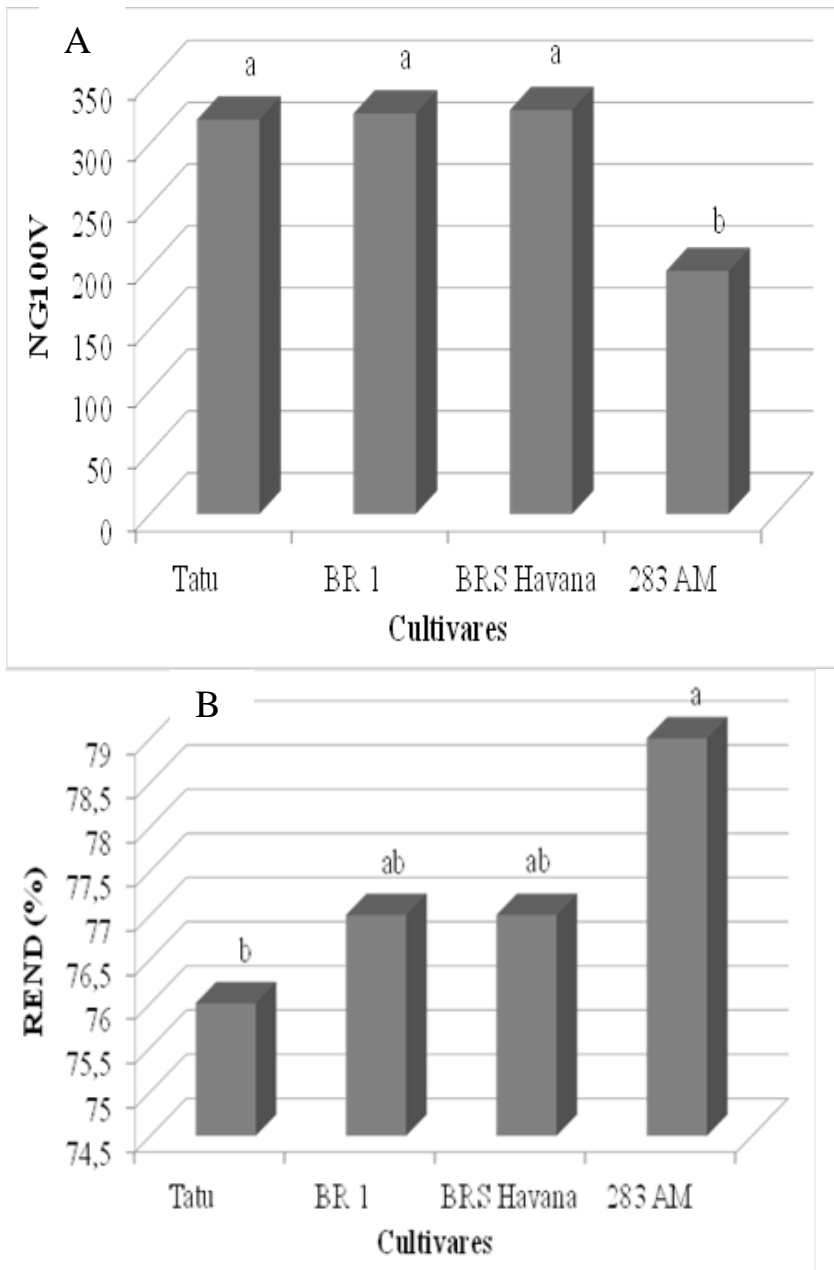

Figura 5. Número de grãos de 100 vagens (NG100V) -A e rendimento (REND) - B de amendoim de quatro cultivares em dois tipos de plantio.

Os resultados obtidos nesse experimento, para as variáveis apresentadas nas Figuras 5A e $5 B$, demonstram que dentre estas, qualquer cultivar, em qualquer sistema de plantio, seja direto ou convencional, provavelmente irá apresentar proximidade e até mesmo semelhança no número de grãos em cem vagens, sendo esse componente produtivo uma característica genotípica das cultivares utilizadas neste estudo.

Quando observados os valores médios do rendimento (REND) de grãos de amendoim na Figura 5B, constatou-se que a linhagem 283 $\mathrm{AM}$ foi $79 \%$ superior à cultivar Tatu, apresentando o maior rendimento. Porém 
quando se compara o rendimento da linhagem 283 AM com as cultivares BRS Havana e BR1, elas possuem rendimento de grãos de amendoim semelhantes (77\%), enquanto que a cultivar Tatu, que apresentou um rendimento de 76\%, foi inferior somente à linhagem283 AM, entretanto a cultivar Tatu foi estatisticamente igual as variedades BRS Havana e BR1.

Diversos autores relataram que $\mathrm{O}$ componente produtivo número de vagens por planta é o componente que mais influência no rendimento de grãos e de vagens (CRUSCIOL et al., 2000; NAKAGAWA et al., 2000 e ARAÚJO et al., 2006). Sendo assim, apesar da linhagem 283 AM apresentar menores valores em peso de 100 vagens e maiores valores em peso de 100 grãos, apresentou maior número de vagens, o que fez com que o rendimento de grãos e de vagens nesta cultivar fosse estatisticamente superior.

O rendimento em grãos acima de $70 \%$ é considerado excelente para os critérios de seleção estabelecidos no programa de melhoramento de amendoim da Embrapa. O rendimento em grãos ideal é acima de $70 \%$ e é influenciado pelas condições de fertilidade e pH do solo (SANTOS et al., 2005).

Considerando que o rendimento de grãos e de vagens são as principais características que refletem na produtividade, os resultados revelam que não houve diferenças significativas a 5\%, caracterizando que o tipo de cultivo não influenciou no aumento da produtividade (Tabela 4). Os rendimentos de vagens obtidos pelas cultivares foram inferiores aos observados por Santos et al. (1999) e Santos et al.(2006), que relataram produtividades de $1.833 \mathrm{~kg} \mathrm{ha}^{-1}, 1.965 \mathrm{~kg} \mathrm{ha}^{-1}$ e 1.952 $\mathrm{kg} \mathrm{ha}^{-1}$ para as cultivares BR1, BRS Havana e Tatu, respectivamente.
Tabela 4.Média de produtividade em $\mathrm{kg} \mathrm{ha}^{-1}$ das cultivares e linhagem de amendoim estudadas.

\begin{tabular}{cc}
\hline Variedade & $\begin{array}{c}\text { Produtividade } \\
\text { kgha }^{-1}\end{array}$ \\
\hline Tatu & 1449 a \\
BR 1 & 1703 a \\
BRS Havana & 1742 a \\
283 AM & 1603 a \\
\hline
\end{tabular}

*Médias seguidas de mesma letra na mesma coluna não diferem entre si a $5 \%$ de probabilidade.

As produtividades de vagens e de grãos deste experimento poderiam ter sido maiores, entretanto, as cultivares utilizadas não expressaram todo seu potencial produtivo, devido à ocorrência do ataque de pragas como a Elasmopalpuslignosellus, que ocasionou uma diminuição no estande final da cultura. Uma vez que o índice de rendimento destas foram inferiores aos índices de rendimento das cultivares verificados por Santos et al.(2006). Ainda assim, as cultivares apresentaram médias de rendimentos de vagens e de grãos próximo do esperado.

Já Gonçalves (2004) e Peixoto et al. (2008) relataram que o amendoim apresenta característica de plasticidade, ou seja, possui mecanismos fisiológicos que lhe confere a capacidade de se desenvolver em ambientes edafoclimáticos diversos por meio de modificações na sua morfologia e fenologia, influenciando diretamente nos componentes de produção da planAPta e refletindo na sua produtividade.

Entretanto, as diferenças observadas entre as cultivares estão de acordo com as características agronômicas das cultivares relatadas por Santos et al.(1999) e Santos et al.(2006).

Bastos et al. (2012) trabalharam também com seis genótipos de amendoim, dentre eles a linhagem 283 AM, onde vale ressaltar que a 
linhagem 283 AM foi o tratamento que mais se destacou nas variáveis produtividade e rendimento de grãos.

\section{CONCLUSÕES}

Diante dos resultados de pesquisa apresentados, é possível verificar que dentre os sistemas de preparo do solo, o plantio direto apresenta-se como uma tecnologia promissora para a cultura do amendoim.

As cultivares não demonstraram diferença para número de vagens por planta, peso de área útil e produtividade.

A cultivar BRS Havana apresentou melhor desempenho dentre as cultivares em plantio direto, e para o plantio convencional tanto a BRS Havana quanto BR1 foram superiores em peso de 100 vagens e peso de grãos de 100 vagens.

\section{AGRADECIMENTOS}

Os autores agradecem ao Ministério da Ciência e Tecnologia (MCT), ao Conselho Nacional de Desenvolvimento Científico e Tecnológico (CNPq), à Coordenação de Aperfeiçoamento de Pessoal de Nível Superior (Capes) e ao IFGoiano - Campus Rio Verde, pelo apoio financeiro e estrutural.

\section{REFERÊNCIAS BIBLIOGRÁFICAS}

ARAÚJO, A. C. et al. Cultivares, época de plantio e componentes da produção no consórcio de algodão e amendoim. Revista Brasileira de Engenharia Agrícola e Ambiental, Campina Grande, v.10, n.2, p.357363, 2006.
AZEVEDO NETO, A.; NOGUEIRA, R. J. M. C., MELO FILHO, P. A; Santos, R. C. Physiologicalandbiochemical responses ofpeanutgenotypestowater déficit. JournalofPlantInteractions, v.5, p.1-10, 2010.

BASTOS, F. J. C.; ROCHA, A. C.; SILVA, N. F.; CUNHA, F. N.; SILVA, F. C.; TEIXEIRA, M. B. Desempenho de cultivares e linhagens de amendoim irrigado. Revista Brasileira de Agricultura Irrigada, v.6, $\mathrm{n}^{\circ} .3$, p. 198 - 206, 2012.

BOLONHEZI, D.; MUTTON, M.A.; MARTINS, A.L.M. Sistemas conservacionistas de manejo do solo para amendoim cultivado em sucessão à cana crua.Pesquisa Agropecuária Brasileira, v.42, p.939-947, 2007.

CONAB - COMPANHIA NACIONAL DE ABASTECIMENTO. Acompanhamento da safra brasileira: grãos. Décimo segundo levantamento, Brasília: Conab, 28p. 2013. Disponível em: http://www.conab.gov.br/OlalaCMS/uploads/ar quivos/13_09_10_16_05_53_boletim_portugue s_setembro_2013.pdf. Acesso em: 04 de out. 2013.

CRUSCIOL, C. A. C; LAZARINI, E.; GOlfeto, A. R.; SÁ, M. E. Produtividade e componentes de produção do amendoim da seca em razão da época de semeadura e da aplicação de cálcio. Pesquisa Agropecuária Brasileira, Brasília, v. 35, n. 8, p. 1549-1558, 2000.

DOORENBOS, J.; KASSAM, A. H. Efeito da água no rendimento das culturas. Estudos de FAO: Irrigação e Drenagem, 33, Campina Grande: UFPB, 306p, 1994.

EMBRAPA. Cerrado. Brasília, DF; Empresa Brasileira de Pesquisa Agropecuária: Embrapa Informações Tecnológicas, 2004. 416p.

EMBRAPA. Sistema brasileiro de classificação de solos. Empresa brasileira de 
pesquisa agropecuária. Centro Nacional de Pesquisa de Solos. 2.ed. Rio de Janeiro, Embrapa Solos, 2006. 306p.

FAO. Food Agriculture Organization of United Nations.Disponivelem: http://www.fao.org/corp/statistics/. Acesso em: 04 de out. 2013.

FERREIRA, D. F. Sisvar: a computerstatisticalanalysis system. Ciência e Agrotecnologia(UFLA), v. 35, n.6, p. 10391042, 2011.

GONÇALVES, J. A. Arranjo espacial no crescimento e rendimento de amendoim em duas épocas de semeadura no Recôncavo Baiano. Dissertação (Mestrado em Ciências Agrárias) - Centro de Ciências Agrárias e Ambientais. Universidade Federal da Bahia. 2004. 97p.

HERNANI, L.C.; KURIHARA, C.H.; SILVA, W.M. da. Sistema de manejo do solo e perdas de nutrientes e matéria orgânica por erosão. RevistaBrasileira de Ciência do Solo, v.23, p.145-154, 1999.

INMET. Balanço hídrico decendial no período decorrente do experimento para o amendoim para 0 ano de 2011.Estação Normal INMET - Rio Verde - GO. 2011.

JONGRUNGKLANG, N.; TOOMSAN, B.; VORASOOT, N.; JOGLOY, S.; BOOTE, K. J.; HOOGENBOOM, G.; PATANOTHAI, A. Rooting traits of groundnut genotypes with different yield responses to pre-flowering drought stress. Field Crops Research, v.120, p.262-270, 2011.

KÖPPEN, W.; GEIGER, R. Klimate der Erde. Gotha: Verlag Justus Perthes. Wall-map 150cmx200cm. 1928.

NAKAGAWA, J. et al. Densidades de plantas e produção de amendoim. Scientia Agrícola, Piracicaba, v.57, n.1, p.67-73, 2000.

PEIXOTO, C. P.; GONCALVES, J. A.; PEIXOTO, M. F. S.P.; CARMO, D. O. Características agronômicas e produtividade de amendoim em diferentes espaçamentos e épocas semeadura no Recôncavo Baiano.Bragantia, Campinas, v.67, n.3, p.563568, 2008.

PEREIRA, W. P.; MELO FILHO, P. A.; ALBUQUERQUE, M. B.; NOGUEIRA, R. J. M. C.; SANTOS, R. C. Mudanças bioquímicas em genótipos de amendoim submetidos a déficit hídrico moderado. Revista Ciência Agronômica, v.43, p.766-773, 2012.

SANTOS, R. C. dos; GODOY, J. I. de; FÁVERO, A. P. Melhoramento do amendoim. In: SANTOS, R.C. (Ed. Téc). O agronegócio de amendoim no Brasil. Embrapa Algodão, 2005. p. 123-192.

SANTOS, R. S.; FREIRE, R. M. M.; SUASSUNA, T.M.F.; REGO, G.M. BRS Havana: nova cultivar de amendoim de pele clara. Brasília: Pesquisa Agropecuária Brasileira, v. 41, n. 8. 2006.

SANTOS, R. C.; FARIAS, F.J.C.; RÊGO, G. M.; SILVA, A. P. G.; FERREIRA FILHO, J. R.; VASCONCELOS, O. L.; COUTINHO, J. L. B. Estabilidade fenotípica de cultivares de amendoim avaliadas na região Nordeste do Brasil. Ciência e Agrotecnologia, v.23, p.808812, 1999.

SANTOS, R. C.; REGO, G. M.; SILVA, A. P. G.; VASCONCELOS, J. O. L.; COUTINHO, J. B.; MELO FILHO, P. A. Produtividade de linhagens avançadas de amendoim em condições de sequeiro no Nordeste brasileiro. Revista Brasileira de Engenharia Agrícola e Ambiental, v.14, p.589-593, 2010. 